\title{
INTERNET SECURITY FEELING OF STUDENTS STUDY OF PAYAME NOOR UNIVERSITY
}

\author{
M. Kiani* \\ Department of Social Science, Payame Noor University, Tehran, Iran
}

\begin{abstract}
PURPOSE: The main purpose of this survey is to identify the factors affecting cyber security of students. In this paper, based on theoretical school of Copenhagen, theoretically Coleman, the study of social trust and felling of cyber security will be discussed.

METHODS: This research was used survey in 2015 to assess the students' felling of cyber security PAYAME NOOR UNIVERSITY of Najaf Abad. The research instrument was the questionnaire. Students of PAYAME NOOR UNIVERSITY branch of Najaf Abad with a 7000 population were the statistical population of this study. Based on sample volume formula, the sample size of 300 students were selected from PAYAME NOOR UNIVERSITY center of Najaf Abad. Method of sampling is combination of cluster, simple and class random.

RESULTS: the results of the study showed that there is a significant difference between men and women in cyber security felling. There was a significant difference between individual characteristics and cyber security. Feature of the individual, age, sex, marital individuals.

CONCLUSIONS: Multiple regression analysis showed that among all the variables that were entered into the equation, variables of sex, residence, education, and social trust, in general, can explain about $27 \%$ of cyber security.
\end{abstract}

Key words: Internet security, cyber security, social trust, virtual space, female students, Payame Noor University.

\section{INTRODUCTION}

All Web- based systems are prone to security risks. Many scholars have argued that trust is a prerequisite for successful cyber security. In many areas of security, "Man in the system" is often an important line of defense to identify, prevent, and respond to any threat (1). Traditionally, this area is concentrated in the real world, ranging from mainstream public safety in crowded spaces and border control, through the identification of suspicious behavior, hostile identify and implement counter-terrorism initiatives. In this case, security is usually the responsibility of front line staff with defined roles and responsibilities of the organizational protocols (2). It offers a useful way of understanding the requirements and non-functional requirements such as quality assessment, strength, honesty system (security), and flexibility. (3). Many scholars have argued that "What is cyber-security?

\footnotetext{
*Correspondence to: Mojdeh Kiani, Department of Social Science, Payame Noor University, Tehran,Iran,mjdhkiani@yahoo.com
}

Cyberspace is defined, according to Oxford English Dictionary (4), as the notional environment in which communication over computer networks occurs."(5). Shen and others (6) noted that the incredible growth of the Internet is widely used and unprecedented comfort brought to their users. However, an increasing amount of unwanted traffic, such as spam and malware, extremely difficult for both users and Internet service providers (ISP), which caused widespread public, concern which caused wide public concern. International Trust Management (GTM) system was proposed and demonstrated that accurate, robust and effective in controlling unwanted traffic on our previous work (7). Bahtiyar et al.(8) in their paper "Security similarity based trust in cyber space" present a model for enhancing security in the case of a service experience with similar systems, using our security practices for the calculation of confidence (9). Yan noted that Chen et al. Proposed an approach to quantitatively measure Compare the quality and access control mechanisms (ACMs) across platforms 
in the article "Evaluating and comparing quality control access to different operating systems." A prototype implementation of the proposed method showed more effectiveness (10). McSweeney argues that the concept of social security is too subjective and objective position against the adoption of this concept in favor of traditional concepts of security (11). Barry Buzan noted that human communities affected by the five basic assumption in the field of security studies: the military, political, social, economic and ecological (biological environmental) that these sections do not operate in isolation from each other and each one of them has a major focus on the issue of security and the method for setting priorities, which are connected to each other through strong communication (12). Wang and Emurian (13) provide an Overview of the nature and concepts of trust from a multidisciplinary perspective, and it reviews studies that examine the elements of online trust. Also, a trust- inducing the expression of interface design features of the literature is presented. They noted that E-commerce fragile future without climate is generally reliable. Building consumer trust in the Internet presents a challenge for online merchants and a research topic of increasing interest and importance. The design features four dimensions, namely (1) Graphic Design (2) structure, (3) the design and content, and (4) social design cues were classified. Using specific design features in the context of ecommerce web interface, online merchants so it may be desirable to predict the strengthening of trust in your customers. Jackson (14) investigated the social security and adherence to formal rules concludes that the notion of social cohesion, trust and informal social control and interpretation of values, norms and ethics of the constituent assembly, just as the interpretations of the broken - window and insecurity in shaping the perception of risk involved. Because it violates the trust that they keep hidden negative expectations lead to feelings of insecurity (14). Cyber Trust ranges of issues present themselves:

- User acceptance of on-line transactions are balanced against the risks and benefits estimated.

- Trust in the technology used to produce interactions (e.g., perception of open protocols secure against network vulnerabilities) as well as the validity of individuals or organizations that are part of the engagement process (15). Coleman suggests that as a rational account of human behavior, trust can only be produced in informal, small, closed and homogeneous communities which are able to enforce normative sanctions (16). Another approaching is concept of the "radius of trust." If a group's social capital produces positive externalities, the radius of trust can be larger than the group itself. The most important and the most common grounds for confidence that our goal is to estimate the reliability of it as "whether or not we trust?" Consider the case. Usually with a variety of "trust rate" face (16). Coleman initially proposed that rely on understanding received help from other people like a "slip of credit", which relates to the aid received by it mandatory that the person or she feels. (17). Nicholas Luhman in security theory with emphasis on the classification of the individual to the realm of the familiar and unfamiliar area offers. Luhman vision insecurity arises when a person puts up an unfamiliar world. The only way to make him feel secure in unfamiliar trust in abstract systems knows (18). "Luhmann distinguished system trust By stating that it is generated through our communication In social systems Where 'media' such As money, truth, love and power are functions of social systems that help to establish trustful relations among individuals" (19). According to PAYAME NOOR UNIVERSITY is the E-learning University in IRAN, the PAYAME NOOR UNIVERSITY is the areas that studied. One of the main reasons people are reluctant to use the locate system of web-based, e-learning systems. It is important to understand the needs and fears of users when they use the e-learning system. What are the factors affecting students' sense of cyber security? One of the major factors affecting cyber security is social trust students. Is social trust is associated with cyber security? Trust is the cornerstone of social interaction and facilitates social relations. Emphasize the need to study the pathology of cyber security related. The younger generation, especially students, to what extent virtual networks and trust? And a virtual relationship feels safe? Trust is an important conceptual idea is still entrenched is an example. Cyberspace, cyberspace relationships with real features is its high specific capacity and cannot be taken lightly. Access different world, cyberspace security is jeopardized. Is the level of social trust is associated with cyber security? (2)Is there a relationship between the individual characteristics (gender, age, marital status) and cyber security?

\section{Conceptual Model}

In this paper, based on theoretical and conceptual framework of the Copenhagen 
school, the most important approach to security, which implies, Security concept based on theories of scientists schools, and has been investigated theoretically Coleman, the study of social trust and sense of cyber security is addressed by Figure 1.

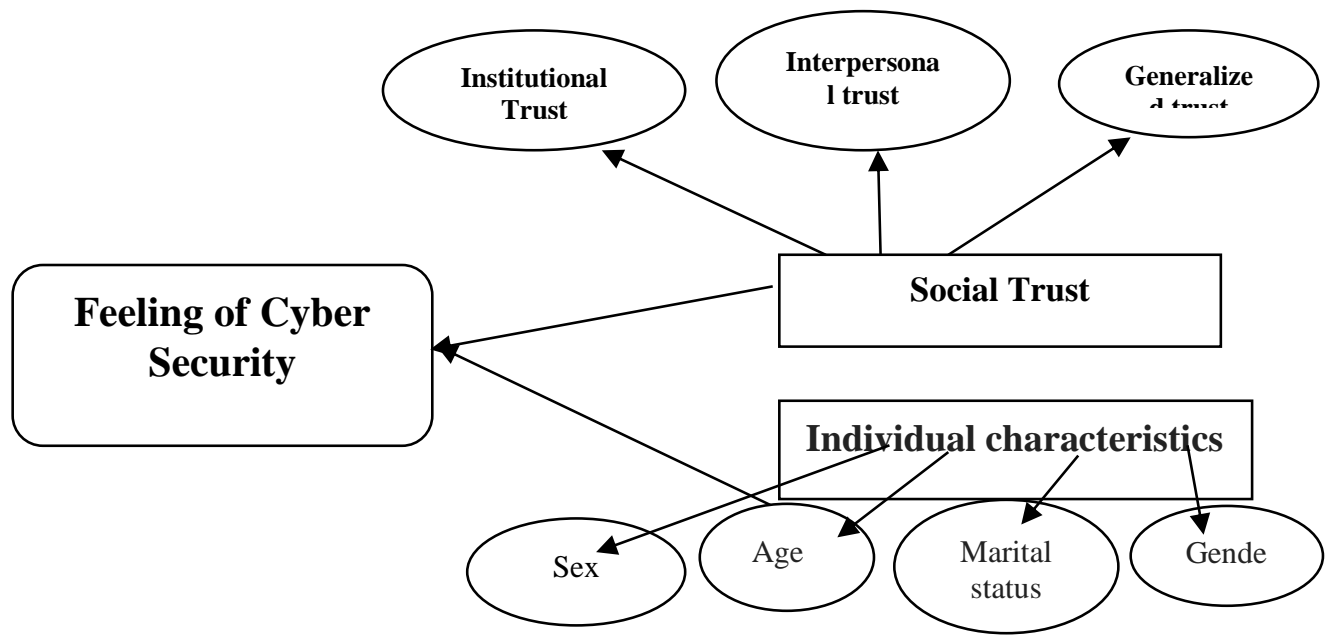

Figure 1. Theoretical model of social trust and a sense of cyber security

\section{METHODOLOGY OF THE RESEARCH}

This study is to survey the students PAYAME NOOR UNIVERSITY's cyber security. Besides the method of scrolling documents and research library for the study of the theoretical and empirical literature used. Assessment tool, a questionnaire is made.

The statistical population and sample students of PAYAME NOOR UNIVERSITY branch of Najaf Abad with 7000 population are statistical population of this study. Based on sample volume formula, the sample size of 300 students were selected from PAYAME NOOR UNIVERSITY center of Najaf Abad. Method of sampling is combination of cluster, simple and class random.

\section{Statistical Methods}

In this research uses individuals as units of analysis. To analyze the relationship among variables and test hypothesis, correlative coefficient and multi variable regression have been used. Based on main indices mentioned in the conceptual definition of social trust and cyber security, some indicators were introduced and the evaluation of their nominal validity and reliability of each one of indices was determined regarding Corenbach Alpha coefficient.

\section{Hypotheses and research questions}

(1) Is the level of social trust is associated with cyber security?

(2) Is there a relationship between the individual characteristics (gender, age, marital status) and cyber security?

\section{FINDINGS}

$67.5 \%$ of respondents were female, and the rest are male. $64.5 \%$ of respondents were single and $32.8 \%$ was married. $34.5 \%$ of respondents were median income and about $16 \%$ were high-income levels. 54\% of respondents have confidence in young people and $22.3 \%$ in middle-aged people in cyberspace. About $60 \%$ of respondents are confident the web chats. About $64 \%$ female trust in cyberspace.

$54 \%$ of respondents trust to youth and, $22 \%$ of respondents to middle-aged people have confidence in cyberspace. About 60 percent of respondents have low confidence in the web chat. About $64 \%$ of respondents have confidence in female in cyberspace.

\section{Testing hypotheses}

there is a significant relationship between the social trust and sense of cyber security.

Table 1 illustrates that there is a significant relationship between the social trust and sense of cyber security related. Because the sig $<0.05$ is also a direct relationship.

Table 1. The coefficient of correlation between social trust and a sense of cyber security

\begin{tabular}{|l|l|l|}
\hline$N$ & Sig & Correlation \\
\hline 296 & $0 / 00$ & .375 \\
\hline
\end{tabular}




\section{KIANI M.}

Based on Table 2 there was a significant difference between men and women in cyber security. For comparison, the dependent variable is the cyber security of the independent variable gender-independent twosample T-test we use (Table 2). The results are summarized in the following tables. The results showed that 26 percent of the Compare results to sex differences in two out of a sense of cyber security in terms of equality of variance are summarized in the table below. Compare results to sex differences in two out of a sense of cyber security in terms of equality of variance are summarized in the table below. According to the results, there is a significant difference between men and women in cyber security for $0.05<\mathrm{Sig}$

Table 2. T-test comparing the mean safer cyber sex

\begin{tabular}{|l|l|l|l|}
\hline $\begin{array}{r}\text { The mean of two } \\
\text { independent samples }\end{array}$ & Sig & Df & T \\
& & & \\
\hline .284 & .014 & 254 & 2.497 \\
\hline
\end{tabular}

Based on these findings, there was a significant difference between individual characteristics and cyber security. Feature of the individual, age, sex, marital individuals. According to the Table 3, the correlation between age and the felling of cyber security is significant.

Table 3. Correlation between age and cyber security

\begin{tabular}{|l|l|l|}
\hline $\mathrm{N}$ & Sig & Correlation \\
\hline 296 & .03 & -.191 \\
\hline
\end{tabular}

The results of both gender and marital status and cyber security are a significant relationship. The highest sense of cyber security is allocated an average of 85 female students. Top 90 single students with the average level of cyber security related.

Regression analysis of the effects of independent variables on cyber security

To fit an appropriate model variable backward methods have been used. In fitting a model of cyber security, $\mathrm{Y}$ is the dependent variable, and the gender, marital status, age, course, father's education, mother's education, education, income, place of residence, social trust, profession, place of birth, occupation, type of residence, history of internet the amount of hours of Internet use per day, age, visiting chat rooms and social-economic status are independent variables.

$$
\begin{aligned}
& Y=1.01-0.415 \mathrm{X}_{1}-0.377 \mathrm{X}_{2}-0.04 \mathrm{X}_{3}-0.185 \mathrm{X}_{4}-0.059 \mathrm{X}_{8}+0.007 \mathrm{X}_{11}+0.771 \mathrm{X}_{10} \\
&+ 1.544 \mathrm{X}_{12}-0.561 \mathrm{X}_{14}-0.136 \mathrm{X}_{15}+0.226 \mathrm{X}_{16}+0.536 \mathrm{X}_{17}+0.151 \mathrm{X}_{18} \\
&+0.085 \mathrm{X}_{13}-0.264 \mathrm{X}_{19}+\varepsilon
\end{aligned}
$$

In the Table 4 the results of the regression

\begin{tabular}{|c|c|c|c|c|c|}
\hline \multirow[t]{2}{*}{$\begin{array}{c}\text { Significant } \\
\text { level. }\end{array}$} & \multirow[t]{2}{*}{ The t-test } & \multirow{2}{*}{$\begin{array}{c}\text { Standardized } \\
\text { coefficients } \\
\begin{array}{c}\text { The amount } \\
\text { of beta }\end{array}\end{array}$} & \multicolumn{2}{|c|}{$\begin{array}{c}\text { Standardized } \\
\text { coefficients are } \\
\text { not }\end{array}$} & \multirow[t]{2}{*}{ Variables } \\
\hline & & & Beta & B & \\
\hline .00 & 6.4 & - & 0.432 & 2.77 & Constant \\
\hline .001 & -3.28 & 0.191 & 0.113 & -0.37 & Sex \\
\hline .005 & -2.83 & -.166 & .274 & -.775 & Lodging \\
\hline .00 & 7.023 & .4 & 0.076 & 0.536 & Social trust \\
\hline 0.00 & -3.86 & -.227 & 0.049 & -.188 & $\begin{array}{c}\text { Parent } \\
\text { Education }\end{array}$ \\
\hline
\end{tabular}
coefficients are summarized.

Table 4. Regression coefficients cyber security 
Using multiple regression models, the effect of the independent variable on the dependent variable is measured. Multiple correlation coefficients for the effect of independent variables on the dependent variable in the model are measured. The adequacy of the model was tested by Watson cameras that represent a suitable model.

Multiple regression analysis revealed that among all the variables that were entered into the equation, sex, residence, education, and social trust, place of residence, social trust, profession, place of birth, occupation, type of residence, history of internet the amount of hours of Internet use per day, age, visiting chat rooms and social-economic status, in general can explain about $27 \%$ of cyber security.

\section{CONCLUSION}

This article in response to the questions what are the factors affecting students' sense of cyber security? Is the level of social trust is associated with cyber security? Is there a relationship between the individual characteristics (gender, age, marital status) and cyber security? With The survey method investigated PAYAME NOOR UNIVERSITY students on cyber security felling when students use e-learning systems re more concerned about security issues.67.5 percent of respondents were female and the rest male. According to the results, there was a significant relationship between social trust and feeling of cyber security. Nicholas Luhmann security classification based on the theory of the individual to familiar territory and unfamiliar areas. The feeling of Insecurity occurs when a person puts a foot into an unfamiliar world. About 60 percent of respondents have low confidence in the web chat. According to the results, the relationship between the social trust and the feel safe in cyber is significant. This is a direct relationship. That means that the higher social trust, the feeling was more cyber security. The relationship between sex and cyber security is significant (20).

The relationship between age and cyber security is a significant inverse correlation. Multiple regression analysis showed that among all the variables in the equation have, sex, residence, education, and social trust, the total can explain about $27 \%$ of cyber security Cyberspace has a high capacity. Understanding the causes of actual and potential cyber security. On the Castells (21), the social network has taken all domains of social life in such a society, people are constantly communicating with each other to improve their social structure.

The cyber-security, it can be very difficult to get the user's needs. With regard to cyber security issues before it, it is often a challenge to identify and access to users who are interested in is the key to any investigation. For example, the user's trust is violated (e.g., via a social networking site or a phishing attack), users may feel shame, guilt offering to pay money to bogus, and you may want to draw attention to themselves (20).

According to Coleman's theory, investor confidence and forced people to help each other and get made. Does the development of the networks of homogeneous and heterogeneous networks, more friends, acquaintances and colleagues, social skills, interpretation of symbols in the network of mutuality and trust in cyberspace, is a reflection? What caused you to trust each other feel secure? Is the network of relationships between men and women based on gender differences, cyber security has been reproduced? What is more important to consolidate the knowledge of the trustee of the trust relationship of action and reaction that leads to trust him? Do join us in cyberspace, with strong ties to family, friends and neighbors to support continued strong link? (20).

Cyberspace, cyberspace real relationships with features that cannot be without the knowledge of high-capacity and can be neglected. And access various features from the world of cyberspace, familiar and unfamiliar jeopardized the security of cyberspace. The results of this study, the gender effect on cyber security.

\section{REFERENCES}

1. Saikayasit, R., Stedmon, A.W., Lawson, G., Fussey, P. User requirements for security and counter-terrorism initiatives. In: Vink, P. (Ed.), Advances in Social and Organizational Factors. CRC Press, Boca Raton, FL, p. 256-265. 2012.

2. Alex W. Stedmon, Dale Richards, Siraj A. Shaikh, John Huddlestone, Ruairidh Davison. Chapter 5 -Cyber-specifications: capturing user requirements for cybersecurity investigations. Cyber Crime and Cyber Terrorism Investigator's Handbook, P. 43-58. 2014.

3. Lohse, M., 2011. Bridging the gap between users' expectations and system evaluations. In: 20th IEEE International Symposium on Robot and Human Interactive Communication, 31 July-3 August 2011, 
Atlanta, GA, USA. p. 485-490. Quoted Alex et al. 2014.

4. Oxford English Dictionary, Oxford University Press, Oxford, UK. 2013.

5. Hyslop, M.P. Cyber-Security Hazards in Society. University of Northumbria. Springer, UK. 2013

6. Shen Yue, Yan Zheng, Raimo Kantola. Analysis on the acceptance of Global Trust Management for unwanted traffic control based on Game theory. Computer and Security 47. p. 3 -2 5. 2014.

7. Yan Z, Kantola R, Shen Y. A generic solution for unwanted traffic control through trust management. New Rev Hypermedia Multimedia; 2013. Quoted Shen et al., 2014.

8. Bahtiyar a, b, Mehmet Ufuk Cag layan. Security similarity based trust in cyber space. Knowledge-Based Systems (52). p. 290-301. 2013.

9. Yan Zheng Guojun Wang, Valtteri Niemi, Deng Robert H. Special issue on trust in cyber, physical and social computing. Computer and Security. 2014. from http://dx.doi.org/10.1016/j.cose.2014.09.00 50167-4048/C 2014 Published by Elsevier Ltd.

10.Panic, Branka, Societal security and identity. University of Belgerad. 2009.

11.Buzan, B., Waever, O. and De Wilde, J. Security - A New Framework for Analysis, Colorado: Lynne Rinner Publishers, Inc., Boulder. 1998.

12.Wang, Ye Diana, Emurian, Henry H. An overview of online trust: Concepts, elements, and implications. Computers

Human Behavior 21. p. 105-125. 2005.

Available online 18 February 2004.
13.Jackson, Jonathan, Introducing Fear of Crime to Risk Research." Risk Analysis. Vol.26.No.1, p.253-64. 2006.

14.T, Hehen, the possibility of social security in an insecure society. Ageing societies, new sociology $6^{\text {th }}$ conference of European sociological Association $23^{\text {rd }}-26^{\text {th }} .2003$

15.Beldad, A., de Jong, M., Steehouder, M. How shall I trust the faceless and the intangible? A literature review on the antecedents of online trust. Comput. Hum. Behav. 26, p. 857-869. 2010

16. Coleman, J.S. Foundations of Social Theory. Cambridge, MA: Belknap Press of Harvard University Press. 1990.

17.Leung: 2010 quoted Kiani, 2012.

18.Jalava. Jane, from norms to trust: The Luthmannian Connevtion between Trust and system, University of Helsinki, sage publication, London. 2003.

19.Niklas Luhmann. Intr. G. Poggi, Chichester and others. Trust and Power. John Wiley \& Sons. 1979. (Original work published 1968).

20.Kiani, Mojdeh. Social Network Of Men And Women And Trust In Police A Case Study in Esfahan. 6(4). P. 685-666. 2012.

21.CASTELLS MANUEL. Communication, Power and Counter-Power in the Network Society. International Journal of Communication.1, p. 238-266. 2007. Available at http://ijoc.org. Boston, USA.I3P. 2013. Available at: http://www.thei3p.org/ (accessed 27.10.13.) 